This document is confidential and is proprietary to the American Chemical Society and its authors. Do not copy or disclose without written permission. If you have received this item in error, notify the sender and delete all copies.

\title{
Tuning the Magnetic Properties of Carbon by Nitrogen Doping of its Graphene Domains
}

\begin{tabular}{|r|l|}
\hline Journal: & Journal of the American Chemical Society \\
\hline Manuscript ID: & ja-2014-12897m.R1 \\
\hline Manuscript Type: & Article \\
\hline Complete List of Authors: & $\begin{array}{l}\text { Ito, Yoshikazu; Tohoku University, } \\
\text { Christodoulou, Christos; Humboldt Universität zu Berlin, } \\
\text { Nardi, Marco; Humboldt-Universität zu Berlin, Institut für Physik } \\
\text { Koch, Norbert; Humboldt Universität zu Berlin, } \\
\text { Kläui, Mathias; Johannes Gutenberg University Mainz, Institut für Physik } \\
\text { Sachdev, Hermann; MPI Mainz, } \\
\text { Müllen, Klaus; Max-Planck-Institute for Polymer Research, }\end{array}$ \\
\hline
\end{tabular}

\section{SCHOLARONE \\ Manuscripts}




\title{
Tuning the Magnetic Properties of Carbon by Nitrogen Doping of its
}

\section{Graphene Domains}

\author{
Yoshikazu Ito $^{1 \#}$, Christos Christodoulou ${ }^{2}$, Marco V. Nardi ${ }^{2}$, Norbert Koch ${ }^{2}$, Mathias Kläui ${ }^{3}$, Hermann \\ Sachdev $^{1 *}$, Klaus Müllen ${ }^{1 *}$ \\ ${ }^{1}$ Max-Planck-Institute for Polymer Research, Synthetic Chemistry, Ackermannweg 10, 55128 Mainz, Germany. \\ ${ }^{2}$ Humboldt-Universität zu Berlin, Institut f. Physik, Brook-Taylor-Straße 6, 12489 Berlin, Germany. \\ ${ }^{3}$ Physik-Institute, Johannes Gutenberg Universität Mainz, Mainz, Germany.

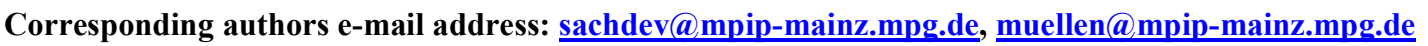

\begin{abstract}
Here we present the formation of predominantly $\mathrm{sp}^{2}$ - coordinate carbon with magnetic and heteroatom- induced structural defects in a graphene lattice by a stoichimetric dehalogenation of perchlorinated (hetero-)aromatic precursors [hexachlorobenzene, $\mathrm{C}_{6} \mathrm{Cl}_{6} \quad(\mathrm{HCB})$, and pentachloropyridine $\left.\mathrm{NC}_{5} \mathrm{Cl}_{5},(\mathrm{PCP})\right]$ with transition metals like copper in a combustion-synthesis. This route allows the built-up of a carbon lattice by a chemistry free of hydrogen and oxygen compared to other pyrolytic approaches and yields in either nitrogen doped or undoped graphene domains depending on the precursor. The resulting carbon was characterized by scanning electron microscopy (SEM), transmission electron microscopy (TEM), Raman spectroscopy, photoelectron spectroscopy (XPS) and by SQUID magnetometry to gain information on its morphological, chemical and electronic structure and on the location of the nitrogen atoms within the carbon lattice. A significant lowering of the magnetization was observed for the nitrogen doped carbon obtained by this method, which exhibits less ordered graphene domains in the range of approx. 10-30 nm as per TEM analysis compared to the non- doped carbon resulting from the reaction from HCB with larger graphene domains as per TEM and the presence of a $2 \mathrm{D}$ mode in the Raman spectra. The decrease of the magnetization by nitrogen doping within the $\mathrm{sp}^{2}$ - coordinate carbon lattice can be attributed to an increase of pyrrol-type defects along with a reduction of radical defects originating from five-membered carbon ring structures as well as changes in the $\pi$-electron density of edge states.




\section{KEYWORDS: Magnetism, Graphene, Nitrogen Doping, Raman Spectroscopy, SQUID}

\section{INTRODUCTION}

Pure, blended or functionally modified allotropes of carbon, especially those based on graphene,[1] which is formed from a hexagonal $2 \mathrm{D}$ array of $\mathrm{sp}^{2}$-coordinate carbon atoms, are considered for a manifold of new applications in organic electronics, catalysis and electrochemistry due to its outstanding physical, chemical and technological properties. Moreover, graphene- based, nitrogen doped forms of $\mathrm{sp}^{2}$-coordinate carbon, with the heteroatom placed in defined lattice positions, become increasingly important for applications in conductive films, catalysts, fuel cells,[2-4] lithium batteries,[5] biosensors,[6] field-effect transistors[7-9] capacitors[10] and electrochemical sensors.[11] Therefore, an understanding of the influence of the structural imperfections on the magnetic and electronic properties is necessary. Such lattice defects can be either non-hexagonal atomic arrays or heteroatoms within the graphene lattice with optional charges. The N1s XPS signal is generally used to identify the nature of the specific bonding of nitrogen atoms within a carbon lattice. The description used here is the current terminology found in the literature and XPS database references. The terminology is derived either from molecular structures (e.g. "pyridinic, pyrrolic") or resembles the substitution of atoms in the lattice (e.g."substitutional, graphenic, graphitic"). In the literature, the nitrogen lattice positions within a $\mathrm{sp}^{2}$-coordinate graphene domain are usually categorized as pyridinic, graphitic(graphenic), pyrrolic and aromatic sites, although a manifold of other structures is feasible and characterized by photoelectron spectroscopy (graphenic $398.1 \mathrm{eV}$, pyridinic $397.9 \mathrm{eV}$, pyrrolic $400.3 \mathrm{eV}$, graphitic: 400.5/401eV, aromatic $399.3 \mathrm{eV}$, also including 5-membered heteroaromatic structures with one or more nitrogen atoms) [12-18]. Thus, nitrogen can be considered as a chameleon within a $\mathrm{sp}^{2}$-coordinate carbon lattice due to the manifold options of its positioning and bonding.[19] Some of these possibilities are illustrated in figure 1. The replacement of nitrogen atoms in the graphene lattice results in changes in the electronic density of states (DOS)[20], and graphitic nitrogen can provide $\pi$-electrons close to the Fermi level of graphene in contrast to pyridinic and pyrrolic 
nitrogen atoms.[21] Whereas the electronic properties of carbon materials are widely investigated in the literature,[22,23] there are only few reports dealing with their magnetic behavior. For example, edge states located at zig-zag structures were identified by theory [24,25] and experiments [26,27,28] to contribute to the magnetism of graphene layers. There are still remaining key questions, e.g. how the magnetic properties of carbon materials are influenced by the introduction of dopants like nitrogen atoms, or if other structural motifs, such a. radicals,[29,30,31] are responsible for the magnetism. Doped carbon materials can be prepared by pyrolysis,[32] by chemical vapor deposition,[33] by combustion-synthesis from halogenated hydrocarbons [34-37] and by reactive etching from carbides.[38]

According to an approach dating back to Henry Moissan,[39,40] it is possible to treat perhalogenated aliphatic or (hetero-)aromatic molecular precursors in a stoichiometric reaction with reactive metals to form carbonaceous materials. Since pyridinic structural elements are discussed to effect electronic changes in the graphene lattice, especially pyridines and perhalogenated pyridines can be considered as suitable precursors to enhance these structural motifs in the resulting network of threefoldcoordinate carbon atoms. Here we present a synthesis of graphene-based, nitrogen doped carbonaceous materials by reacting perhalogenated molecular precursors (pentachloropyridine and hexachlorobenzene as a reference) with transition metals like $\mathrm{Cu}, \mathrm{Ni}, \mathrm{Fe}$, etc. in a stoichiometric ratio instead of using the more reactive alkaline and alkaline earth metals (cf. ref. 5-8 and Figure 1). This route differs from either a strongly exothermic, stoichiometric combustion-synthesis or a catalytic Ullmann-type reaction on surfaces [41] or in solutions and enables the scalable synthesis of hydrogenand oxygen free doped bulk carbons. A generalized equation of the reaction is given by:

$\mathrm{C}_{\mathrm{x}} \mathrm{Hal}_{\mathrm{y}}+\mathrm{M} \rightarrow$ "C $\mathrm{C}-\mathrm{z} "+\mathrm{M}_{\mathrm{a}} \mathrm{C}_{\mathrm{z}} "+\mathrm{M}_{1-\mathrm{a}} \mathrm{Hal}_{\mathrm{y}} "$

Here, " $\mathrm{C}_{\mathrm{x}} \mathrm{Hal}_{\mathrm{y}}$ " represents the perhalogenated precursor molecule, " $\mathrm{C}_{\mathrm{x}-\mathrm{z}}$ " the amount of the newly formed carbon material, " $\mathrm{M}_{\mathrm{a}} \mathrm{C}_{\mathrm{z}}$ " a potentially formed metal carbide and " $\mathrm{M}_{1-\mathrm{a}} \mathrm{Hal}_{\mathrm{y}}$ " the corresponding metal halide. 
We describe in particular the reaction of copper with pentachloropyridine $\left(\mathrm{C}_{5} \mathrm{Cl}_{5} \mathrm{~N}\right)$, because this transition metal is not showing a pronounced carbide formation or a high carbon solubility. The analogous non-doped carbon materials were prepared in a similar manner from hexachlorobenzene $\left(\mathrm{C}_{6} \mathrm{Cl}_{6}\right)$ for reference.

\section{Figure 1}

\section{Formation of Carbon perhalogenated precursor (containing nitrogen)}

(a)

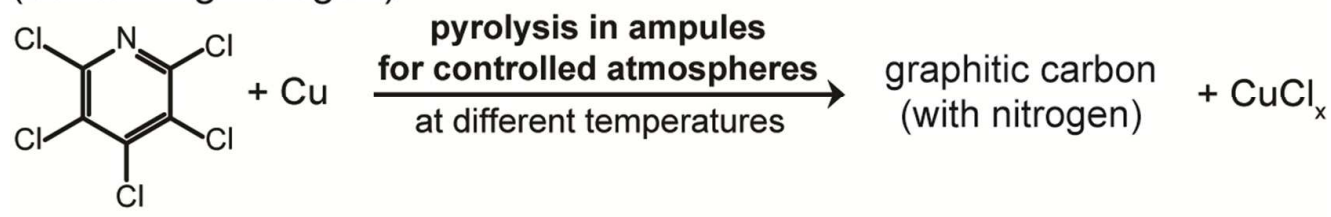

\section{Selected Nitrogen Sites}

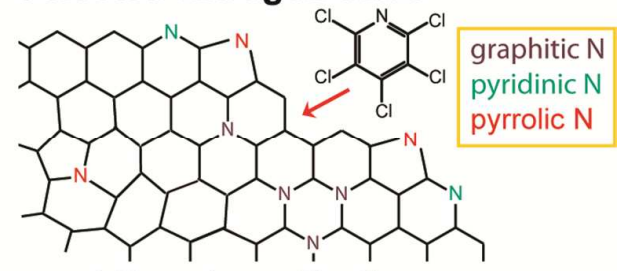

(b)
Formal Interpretation of the Magnetism

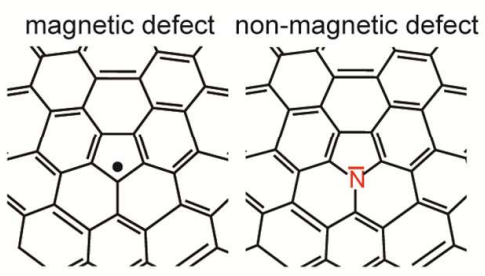

(c)

Figure 1:

a) Schematic illustration of the transition metal assisted dehalogenation of perhalogenated (hetero)aromatic precursors upon pyrolysis; b) potential active nitrogen sites in graphene; c) formal valence bond interpretation, structures and source of the origin for the observed magnetic properties from a chemical point of view indicated by the nitrogen electron lone pair

The morphological and Raman spectroscopic features, magnetic properties and electron core level analysis of the obtained carbons are presented and the influence of the synthesis parameters on the precursor decay and thermal stability of the doped lattice sites is discussed in view of kinetic and thermodynamic aspects.

\section{RESULTS and DISCUSSION}

Pentachloropyridine (PCP) and Hexachlorobenzene (HCB) were dehalogenated with copper (cf. Fig. 1) and the recovered carbon samples were used for further characterization. The dehalogenation of 
pentachloropyridine (PCP) was performed according to equation $(1)$ at $600^{\circ} \mathrm{C}, 800^{\circ} \mathrm{C}$ and $1000^{\circ}$ in an equimolar ratio of copper to chlorine to enable a stoichiometric formation of $\mathrm{CuCl}$ and post treated with hydrochloric acid and the resulting carbons were labeled as PCP600-HCl to PCP1000-HCl, respectively. The acidic quenching of the reaction products allows a removal of copper residues and halide by-products and to separate the sources and nature of the magnetic contributions.

$$
\mathrm{C}_{5} \mathrm{Cl}_{5} \mathrm{~N}+5 \mathrm{Cu} \rightarrow 5 \mathrm{CuCl}+{ }^{\prime \prime} \mathrm{C}_{\mathrm{x}} \mathrm{N} \text { ” }
$$

In order to obtain nitrogen free reference materials, the following reactions were additionally performed: (i) dehalogenation of pentachloropyridine at $1000^{\circ} \mathrm{C}$ with a $1: 2$ molar ratio of copper to chlorine to enable the formation of $\mathrm{CuCl}_{2}$ and workup in hydrochloric acid (PCP1000-HCl-halfCu); (ii) neat pyrolysis of pentachloropyridine at $1000^{\circ} \mathrm{C}$ without copper and without acidic workup (PCP1000-nonHCl); (iii) synthesis of a nitrogen free sample from hexachlorobenzene (HCB) at $1000^{\circ} \mathrm{C}$ with a $1: 1$ molar ratio of $\mathrm{Cu} / \mathrm{Cl}$ to enable stoichiometric $\mathrm{CuCl}$ formation followed by an acidic work-up (HCB1000-HCl); (iv) neat pyrolysis of hexachlorobenzene at $1000^{\circ} \mathrm{C}$ without hydrochloric acid workup (HCB1000-nonHCl). The resulting carbons were recovered as described in the experimental section.

The product distribution of the resulting carbon structures strongly depends on parameters like stoichiometry, onset temperature of the precursor decomposition and halide formation, tendency of carbide formation, stability of the corresponding metal halides as well as the final annealing temperature. For example, the reaction of perhalogenated precursor molecules with alkali and alkaline earth metals, earth metals, or early transition metals can lead to the corresponding metal carbides and metal halides, whereas the reaction with late transition metals can end up in the formation of the corresponding halides and carbonaceous materials due to a reduced tendency of carbide formation.[42] Here, copper was chosen for the dehalogenation reaction to avoid carbide formation and in addition, the resulting copper compounds are either non-magnetic or paramagnetic and their contribution to the magnetic measurements can be subtracted. 
The morphology of the carbon materials obtained from the dehalogenation of PCP and HCB was characterized by SEM (Fig. 2) and TEM (Fig. 3).

\section{Figure 2}
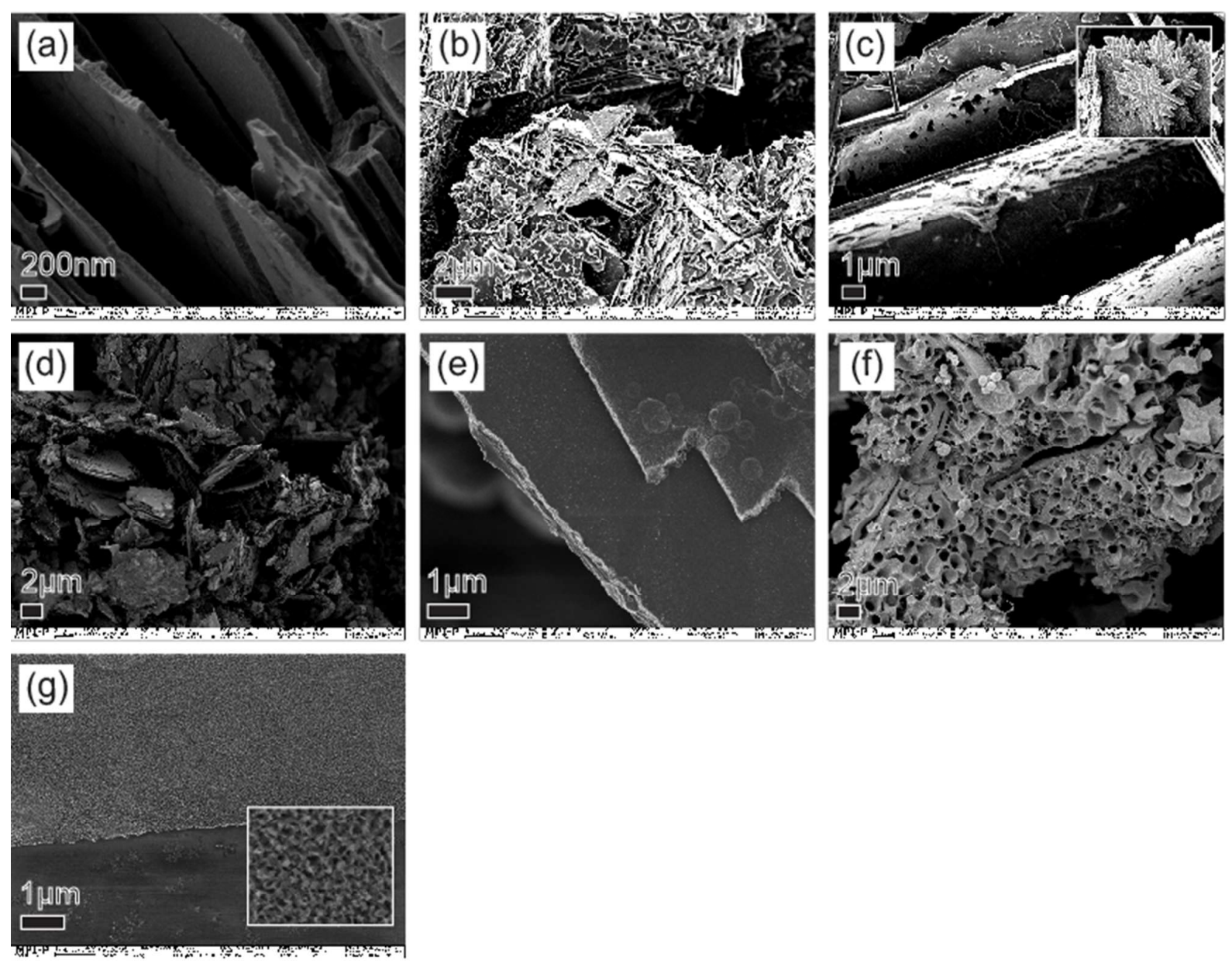

\section{Figure 2:}

SEM images of nitrogen containing carbon materials obtained from the reaction of PCP with an equilmolar amount of $\mathrm{Cu}$ and $\mathrm{Cl}$ (a) at $1000{ }^{\circ} \mathrm{C}$ (b) at $800{ }^{\circ} \mathrm{C}$ and (c) $600{ }^{\circ} \mathrm{C}$, (d) with a half equivalent of $\mathrm{Cu}$ and $\mathrm{Cl}$ at $1000{ }^{\circ} \mathrm{C}$, and (e) without any $\mathrm{Cu}$ at $1000^{\circ} \mathrm{C}$; and graphene containing carbon materials from $\mathrm{HCB}$ as a reference (without nitrogen): (f) from pyrolysis with an equimolar amount of $\mathrm{Cu}$ and $\mathrm{Cl}$ at $1000{ }^{\circ} \mathrm{C}$ and (g) from the neat decay without any $\mathrm{Cu}$ at $1000{ }^{\circ} \mathrm{C}$. 
The formation of distinct plate-like structures is observed in the SEM images of the recovered carbon obtained from dehalogenation of PCP. These structural features start to occur already at $600^{\circ} \mathrm{C}$ in samples prepared from an equimolar copper/chlorine- ratio and become more dominant at higher temperatures [cf. Figure 2(a): individual plates of approx. $100 \mathrm{~nm}$ diameter at $1000^{\circ} \mathrm{C}$; Figure 2(b): dense flakes or platelet- like aggregates at $800^{\circ} \mathrm{C}$; Figure 2(c): dense platelet aggregates at $600^{\circ}$ ]. In samples from a stoichiometry of a copper/chlorine ratio of $1: 2$, which allows formally the intermediate formation of copper(II)chloride $\left(\mathrm{CuCl}_{2}\right)$, these platelets were also observed [Figure 2(d)]. The structures are more regular for a $\mathrm{Cu} / \mathrm{Cl}$ ratio of $1: 1$ than for a $\mathrm{Cu} / \mathrm{Cl}$ ratio of $1: 2$. The applied heat treatment will lead to a thermally induced decomposition of $\mathrm{CuCl}_{2}$ to $\mathrm{CuCl}$ and chlorine due to the limited stability of $\mathrm{CuCl}_{2}$,[43] which enables a different reaction mechanism during the carbon formation and thus affects the resulting morphology. These differences are obvious by comparing Figure 2(a) [PCP1000-HCl] and Figure 2(d) [PCP1000-halfCu].

The morphologies of the nitrogen and non-nitrogen containing carbons obtained from PCP [Figure 2 (a-d)] and HCB [Figure 2(f, g)] indicate a different appearance irrespective of the presence of copper. A comparison of the product morphology resulting from the reaction of PCP with or without copper showed that the neat decomposition of $\mathrm{PCP}$ at $1000^{\circ} \mathrm{C}$ [Figure 2(e), $\mathrm{PCP} 1000$-nonHCl] displays a more regular plate-like appearance than the sample recovered from the reaction of a 1:2 $\mathrm{Cu} / \mathrm{Cl}$ - ratio at $1000^{\circ} \mathrm{C}$ [Figure 2(d), PCP1000-HCl-halfCu]. This is an indication that reactions with PCP generally have lead to a more platelet-like growth morphology, which is not the case for HCB. The neat decomposition of $\mathrm{HCB}$ at $1000^{\circ} \mathrm{C}$ produces an irregular, submicron structured carbon material with a rough surface (Figure $2 \mathrm{~g}$ ), whereas the dehalogenation of $\mathrm{HCB}$ with a $\mathrm{Cu} / \mathrm{Cl}$ ratio of $1: 1$ at $1000^{\circ} \mathrm{C}$ results in a more regular structure with holes up to $1 \mu \mathrm{m}$ (Figure $2 \mathrm{f}$ ).

The platelet-like appearance of the carbon recovered from PCP by neat decomposition and by dehalogenation with copper can be attributed to the decay chemistry of this precursor. Here, the carbon formation takes place within the ternary system $\mathrm{C}-\mathrm{Cl}-\mathrm{N}$ or quaternary system $\mathrm{C}-\mathrm{Cl}-\mathrm{Cu}-\mathrm{N}$, avoiding any hydrogen or oxygen functionalities during the built-up of the carbon structure. 
Figure 3 shows the TEM images of carbon materials recovered after pyrolysis of PCP and HCB at $1000^{\circ} \mathrm{C}$ [neat decomposition and from a equimolar $\mathrm{Cu}: \mathrm{Cl}$ ratio] and in both cases, the presence of carbon containing individual graphene sheets was detected [Figure 3(a-d)].

\section{Figure 3}
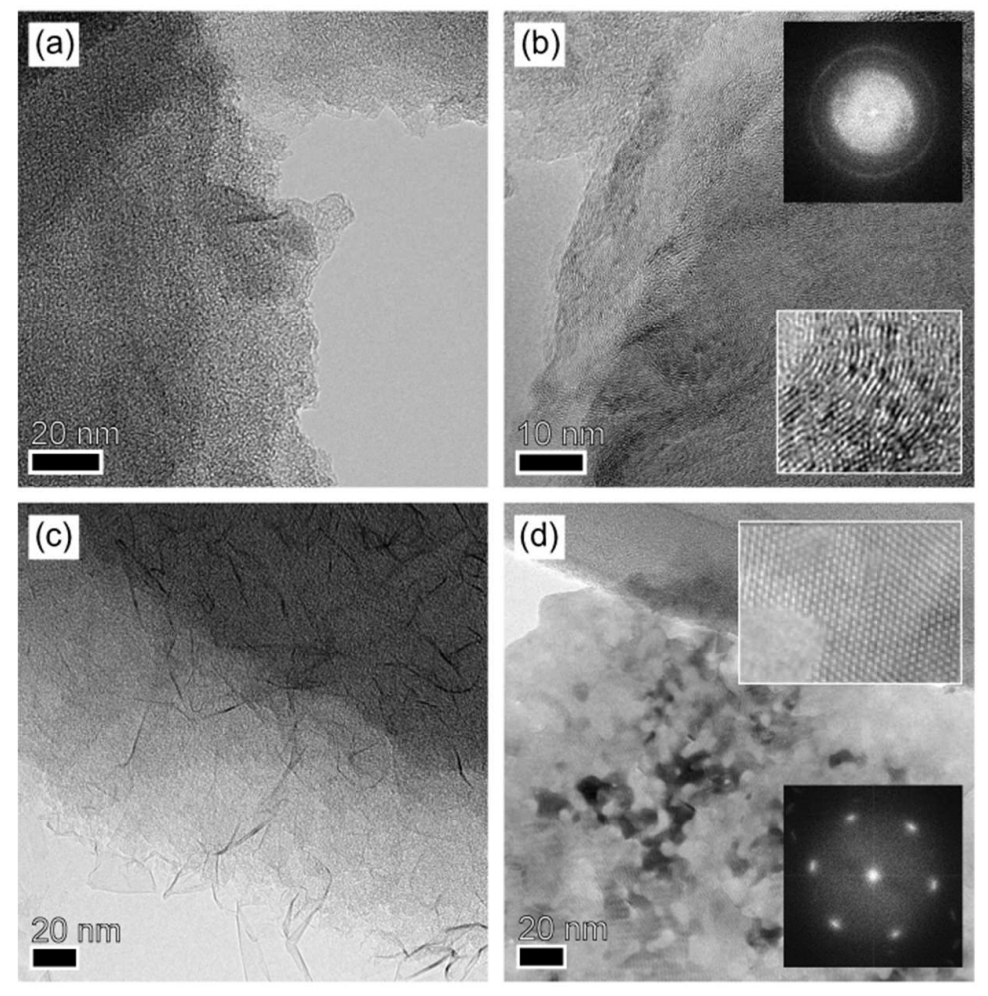

Figure 3:

TEM images of nitrogen containing samples [a) PCP1000 HCl, b) PCP1000 non- $\mathrm{HCl}$ ] and nitrogen free samples [c) $\mathrm{HCB} 1000 \mathrm{HCl}$, d) $\mathrm{HCB} 1000$ non-HCl]. Insets for the non- $\mathrm{HCl}$ treatment indicate the lattice spacing. FFT images [insets in (b) and (d)] demonstrate a randomly orientated graphene lattice or more ordered graphene lattice, respectively formed from HCB.

The lattice reflections of the PCP samples [Figure 3(b)] reveal a disordered structure as indicated by a Debye-Scherrer ring, whereas the HBC sample has a more regularly ordered structure with a diffraction pattern of 6-fold symmetry [Figure 3(d)]. This analysis clearly demonstrates that the decomposition of HCB results in a carbon material containing high quality graphene layers. The reason for the higher degree of disorder observed for PCP must be attributed to the presence of 
nitrogen, which is randomly incorporated into the graphene lattice and therefore results in a break-down of the symmetry.

An XRD powder diffraction pattern helped to identify the nature of the resulting copper halide (Figure S1) $[44,45]$. Before treatment with hydrochloric acid, the presence of $\mathrm{CuCl}$ as a major product is obvious, together with traces for reflections originating from $\mathrm{CuCl}_{2}$. The copper halide peaks have disappeared after the acid treatment.

The nature of binding states of nitrogen atoms incorporated into the carbon lattice was confirmed by XPS. The carbon materials were obtained as powders and embedded in indium foil (containing carbon and oxygen impurities), therefore only the N1s results of the samples are discussed. Figure 4 shows the N1s core level spectra of the samples made from PCP at different temperatures and recovered by acidic workup [PCP600-HCl, PCP800-HCl and PCP1000-HCl]. All samples were measured under comparable conditions in indium foil and indicate the presence of nitrogen. The highest relative N1s intensity is observed for the sample from the lowest preparation temperature (cf. Figure 4). References for N1s binding energies are given for $397.9 \mathrm{eV}$ for pyridine-type nitrogen, $398.1 \mathrm{eV}$ for graphene-type nitrogen and $400.3 \mathrm{eV}$ for pyrrole-type nitrogen in carbon materials. The highest total nitrogen concentration as per signal intensity and the atomic concentration of pyridinic /graphene nitrogen to pyrrole/substitutional nitrogen changes from 1:5.6 [Figure 4(a)] to 1:3.3 [Figure 4(b)] to 1:2.3 [Figure. 4 (c)], which indicates a temperature- dependent selectivity for the formation of graphene- type nitrogen and pyridine type nitrogen at lower temperatures. At higher temperatures, nitrogen is expelled from the carbon lattice (e.g. as $\mathrm{CN}$ radicals) and the residual nitrogen is resting predominantly at heteroaromatic sites at higher binding energy. Those heteroaromatic sites reveal the same shifts as pyrrole type structures. Furthermore, it has to be noted, that even a pyridine precursor needs to undergo a full ring opening and rearrangement to form a (nitrogen substituted) graphene lattice, and thus also the generation of five-membered heteroaromatic ring structures is feasible. This also implies a structural rearrangement of the nitrogen sites during heat treatment and supports the chamaeleon-like behavior of nitrogen atoms in a $\mathrm{sp}^{2}$-hybridized carbon atom network. A 
self-consistent fitting routine was performed and the two major contributions were assigned to pyridinic nitrogen (maxima at $398.6 \mathrm{eV}$ ) and pyrrolic nitrogen. Pyrrolic type nitrogen could not be well separated from other heteroaromatic types of nitrogen structures (both centered at approx. 401 $\mathrm{eV}$ ) due to small differences in the binding energy of ca. $0.6 \mathrm{eV}$ and were fitted as a single component.[46,47]

Figure 4
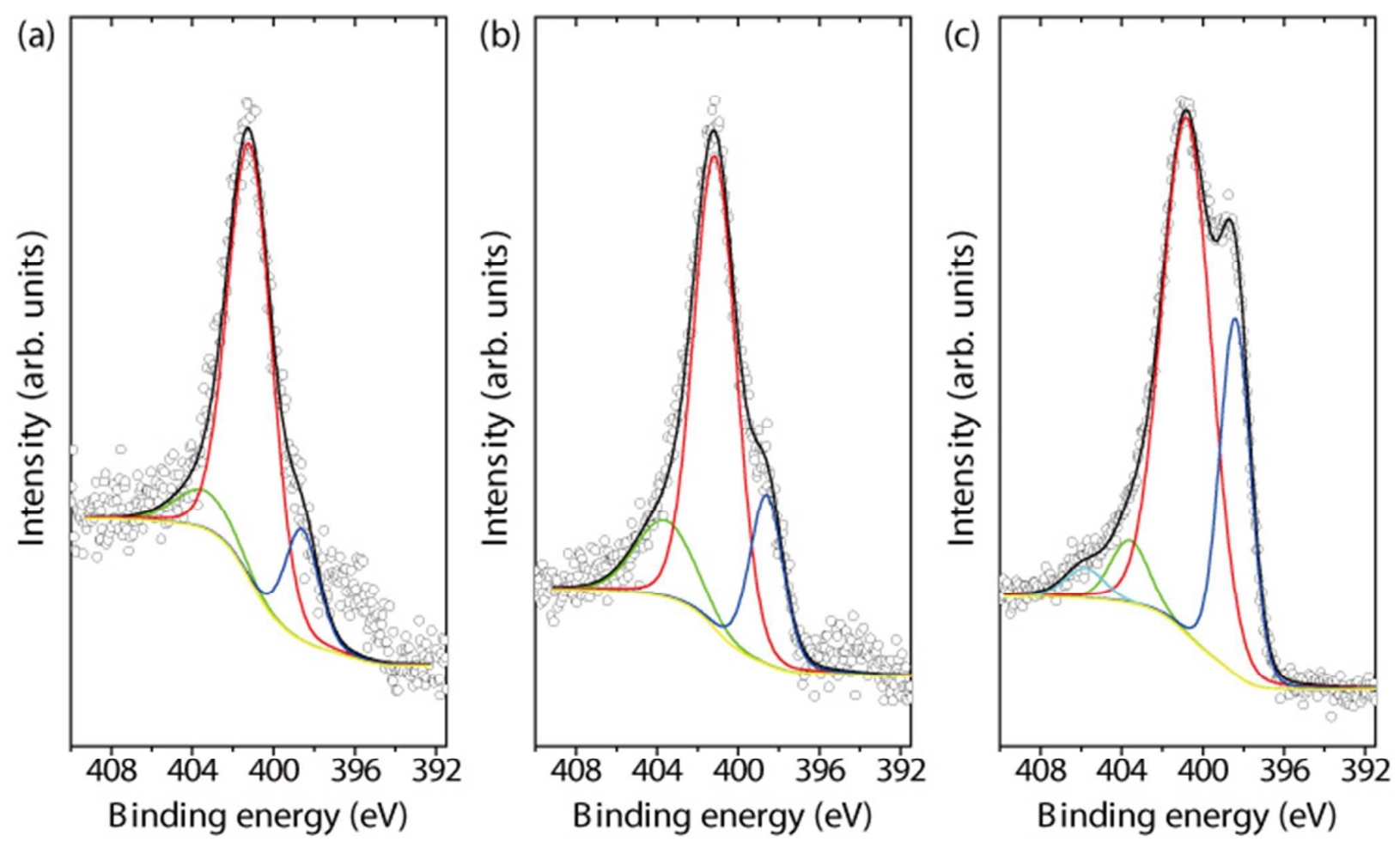

Figure 4: $\mathrm{N} 1 \mathrm{~s}$ core level spectra for a) $\mathrm{PCP} 1000-\mathrm{HCl}, \mathrm{b}$ ), $\mathrm{PCP} 800-\mathrm{HCl}$, and c) $\mathrm{PCP}-600-\mathrm{HCl}$. The contributions of pyridinic nitrogen (at $389.6 \mathrm{eV}$ ) and pyrrolic-graphitic nitrogen $(401 \mathrm{eV})$, as well as shake-up and potential oxidic nitrogen species at higher binding energy, according to the fitting routine, are included in the graphs.

Little is known about the nature of XPS signals of carbonaceous groups containing nitrogen atoms in the energy region above $404 \mathrm{eV}$. Peaks at binding energies higher than $401 \mathrm{eV}$ (Figure 4c, $406 \mathrm{eV}$ ) can be either due to shake-up processes (their relative intensities depend on the applied photon energies; complementary XPS experiments using synchrotron radiation for excitation were performed) or contain contributions from oxidized nitrogen species, or charged or coordinated nitrogen atoms of 
donor type character. A weak intensity at the lower binding energy side of the pyridinic signal is due to spurious contribution from the molybdenum sample holder (control experiments did not show any spectral features below $398.6 \mathrm{eV})$.

Raman spectra (cf. Figure 5, SI Table 1) provided additional structural information of the carbon materials. The pyrolysis temperature dependence reveals less defective graphitic structures for the PCP samples with a decrease of the FWHM (SI Table1) as the preparation temperature increases. The direct formation of graphene domains from HCP is obvious by the presence of the 2D mode.

Figure 5

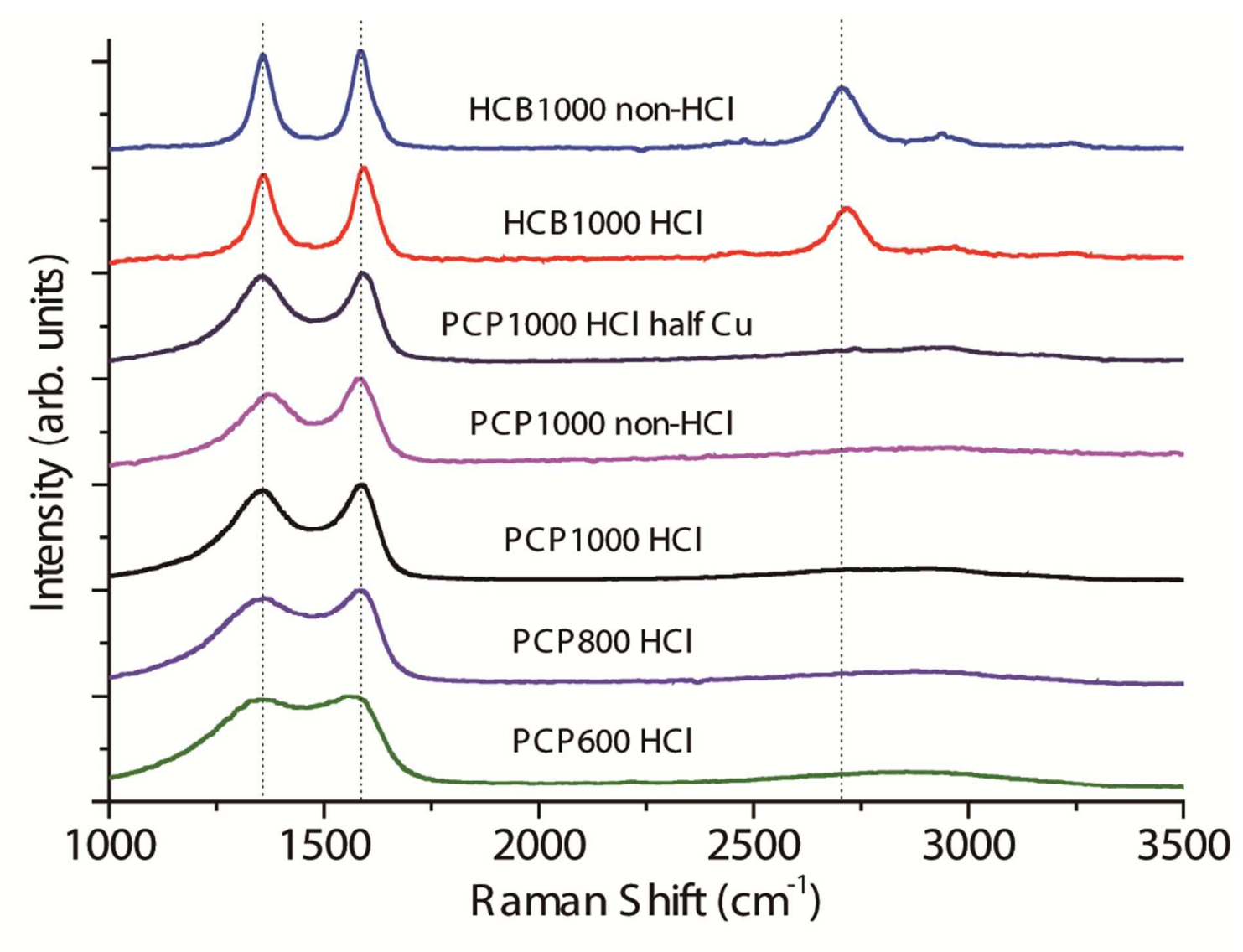

\section{Figure 5:}

Raman spectra of the reaction products obtained from transition metal dehalogenation of (nitrogen containing) perhalogenated PAH's 
A comparison of the samples derived from PCP and HCB indicates a more graphitic structure for HCB due to the presence of the 2D Raman mode, and thus correlates well to the TEM images in Figure 3. Moreover, the $\mathrm{Cu}$-free samples show a higher degree of ordering due to a reduced line width and higher $\mathrm{I}_{2 \mathrm{D}} / \mathrm{I}_{\mathrm{G}}$ ratio's. Magnetic measurements were performed by using a SQUID magnetometry setup to characterize the nitrogen doping effects. Figure 6 shows the magnetization curves at $2 \mathrm{~K}$ together with the corresponding Brillouin functions with different spin (S) fitted for all samples. The analysis of the carbon material obtained from a neat $\mathrm{HCB}$ decomposition (HCB1000-nonHCl) indicates a magnetic interaction resulting from $S=3 / 2$. Since the point defect in graphene [31] leads to $S=1 / 2$, this sample must contain magnetic clusters. Comparable magnetic clusters with $S=2-5 / 2$ are reported for exfoliated HOPG [48]. Such a material reveals highly graphitic structures and the magnetism is considered to result from zig-zag edge structures.[27,49] Moreover, the Raman spectra show a considerable defect band intensity which can be attributed to a disordered lattice containing radical type 5-ring structures derived from a corannulene- type connectivity. [50] Therefore, similar magnetic clusters [cf. Figure 1] might also be present. The dependence of the magnetization on the preparation temperature is depicted for an applied magnetic field of $1 \mathrm{~T}$ in Figure S2, which all follow the Curie-Weiss law with negative Weiss temperatures. The detailed values of magnetization at $5 \mathrm{~T}, S$, spin concentration $\left(N_{\mathrm{s}}\right)$, temperature independent susceptibility $\left(\chi_{0}\right)$ and Weiss temperature $(K)$ were calculated from the fitted Brillouin functions and the Curie-Weiss law and are summarized in Table 1.

Table 1

\begin{tabular}{|c|c|c|c|c|}
\hline & $M(\mathrm{emu} / \mathrm{g})$ & $\chi_{0}\left(10^{-7} \mathrm{emu} / \mathrm{g}\right)$ & $N_{\mathrm{s}}\left(10^{19} \mathrm{spin} / \mathrm{g}\right)$ & Weiss temperature $(K)$ \\
\hline $\mathrm{HCB} 1000 \mathrm{HCl}$ & 2.6 & -5.8 & $30(S=1 / 2)$ & -2.1 \\
\hline $\mathrm{HCB} 1000$ non-HCl & 3.6 & -2.1 & $13(S=3 / 2)$ & -2.7 \\
\hline $\mathrm{PCP} 1000 \mathrm{HCl}$ & 0.67 & -7.0 & $7.7(S=1 / 2)$ & -1.0 \\
\hline PCP800 HCl & 0.30 & -4.2 & $1.1(S=3 / 2)$ & -0.9 \\
\hline PCP600 HCl & 0.58 & -8.7 & $3.2(S=1)$ & -1.2 \\
\hline PCP1000 non-HCl & 0.99 & -6.9 & $11(S=1 / 2)$ & -2.2 \\
\hline PCP1000 HCl half Cu & 0.078 & -5.4 & $0.9(S=1 / 2)$ & -6.2 \\
\hline Nanographene & - & -7.3 & 4.2 & -2.5 \\
\hline
\end{tabular}

Table 1: 
Magnetic properties of of the recovered carbon materials with or without nitrogen [magnetic saturation moment $(M)$, temperature independent susceptibility $\left(\chi_{0}\right)$, spin concentration $\left(N_{\mathrm{s}}\right)$ and Weiss temperature $\left.(\mathrm{K})\right]$

A comparison of the magnetic properties of the materials from the neat pyrolysis of HCB and PCP surprisingly reveals a significantly higher magnetization for the non-nitrogen containing carbon sample. The higher magnetization observed for the material from HCB most likely results from more abundant radical centers, which can be linked to unpaired electronic states, such as e.g. radical-type five-membered ring defects incorporated into the hexagonal graphene lattice.

The decrease of the magnetization for $\mathrm{N}$-doped samples can be explained by different models. One could attribute this effect to the disappearance of radical-type edge states in six-membered heteroatomar ring structures. For states in proximity to zig-zag edges regarding pyridinic and graphitic nitrogen positions, first principle calculations on the partial electron density of states (DOS) have been performed.[51]

In this model, the additional electron density supplied by nitrogen atoms on pyridinic and graphitic positions leads to typical diamagnetic features and a disappearance of magnetic edge states (cf. closed shell, illustrated in Figure 1), which can be explained more simply as chemical resonance effects. In addition, the higher electronegativity of the nitrogen atom in comparison to carbon results in a more localized electron density at the nitrogen positions, too and thus also affects the DOS. Both effects imply that the magnetism of nitrogen doped carbons will become smaller considering edge states only. Since the bulk incorporation of nitrogen atoms outnumbers the amount of rather reactive and unstable edge states, it is also necessary to consider the stability influence of such bonding states (graphitic nitrogen vs. pyrrole-type nitrogen in comparison to a radical type 5-membered carbon ring defect). It is in principle feasible that in nitrogen doped carbon structures, an incorporation of nitrogen into 5-membered ring structures leads to stable, non-radical type, electron-precise pyrrole-type lattice defects (cf. Figure 1c). 
Figure 6

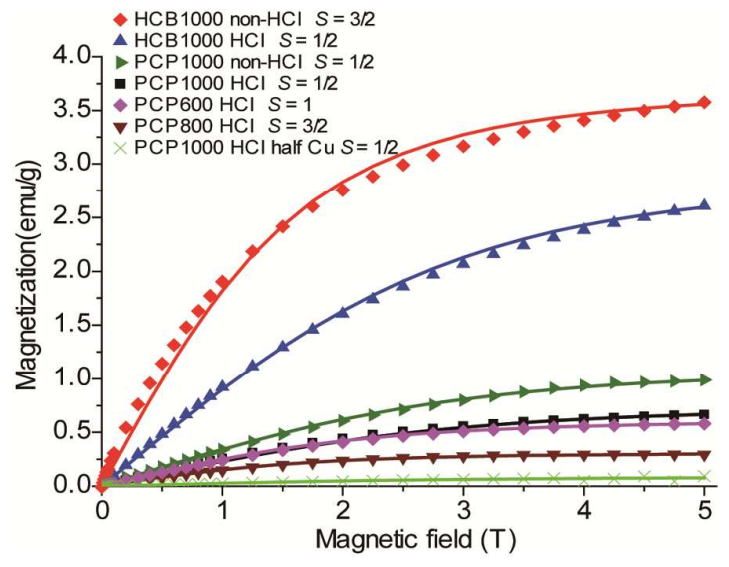

Figure 6:

Magnetization curves of graphitic carbon materials with/without nitrogen obtained from different reaction conditions. Solid lines show the Brillouin function for different spins.

In order to investigate the observed decrease in magnetization by nitrogen incorporation experimentally, hydrochloric acid was used to quench any magnetic anionic type radical defects $(e . g$. 5-7 defects, anionic radical defects, point defects). [52]

The experimental results depicted in Figure 6 indicate lower values for the magnetization of the $\mathrm{HCl}$ treated carbons obtained from PCP (cf. PCP1000-HCl/non- $\mathrm{HCl}$ and $\mathrm{HCB} 1000-\mathrm{HCl} / \mathrm{nonHCl}$ ). Therefore, the total number of radical defects decreases upon $\mathrm{HCl}$ treatment, while some magnetic contributions survive the $\mathrm{HCl}$ treatment. The magnetization of a sample derived from pentachloropyridine $(\mathrm{PCP} 1000-\mathrm{HCl})$ is still lower after the $\mathrm{HCl}$ treatment compared to a sample obtained from hexachlorobenzene $(\mathrm{HCB} 1000-\mathrm{HCl})$. The total number of five-membered radical defects is thus lower for nitrogen-doped samples. When nitrogen is replacing a carbon atom within a 5-membered radical defect, it will become electron-precise by the additional electron from the nitrogen atom, which can contribute to the $\pi$-system of the carbon atom network.

Since the magnetization of PCP samples is smaller for lower reaction temperatures (these samples have a higher gross nitrogen content with additional pyridinic/graphitic nitrogen atoms besides pyrrolic nitrogen atoms as per XPS) and the magnetization increases with the reaction temperature (with a reduced gross nitrogen content in favor for pyrrolic sites), higher reaction temperatures lead to an expulsion of nitrogen from the carbon lattice (e.g. by stable $\mathrm{CN}$ radicals) and thus to an increase of 
the magnetization by generation of radical defects (cf. SI Fig. 3). Thus, the chemical doping by nitrogen incorporation into the graphene lattice allows a reduction of the magnetic response if pyrrole type positions are formed. This enables a tuning of the electronic density of states as well as the magnetic properties of such materials based on $\mathrm{sp}^{2}$-coordinate carbon.

\section{CONCLUSION}

The presented synthetic route based on a stoichiometric dehalogenation of perhalogenated arene and pyridine precursos by a transition metal enables the formation of $\mathrm{sp}^{2}$ - coordinate carbon with graphene domains and the option to incorporate nitrogen especially on pyrrolic bonding sites as indicated by XPS. The formation of highly ordered graphene structures by this approach from HCB was confirmed by TEM and Debye- Scherrer diffraction and the presence of a 2D Raman mode. However, more disordered graphene structures were obtained by the use of an analogous nitrogen containing precursor PCP with a pyridinic carbon ring system. The higher degree of structural imperfection can be attributed to differences in the precursor decay and incorporation of nitrogen atoms into the graphene lattice, which become a mainly pyrrolic nature at higher temperatures as determined by XPS. SQUID measurements indicate a complex origin of the magnetism, which is attributed to radical defects of 5-memebred ring faults within the graphene lattice.

We could thus demonstrate how a nitrogen- doping as induced by decomposition or dehalogenation of PCP results in a decrease of the magnetization. Bulk incorporation of nitrogen outnumbers the rim effects, and therefore, the electronic and magnetic changes induced by lattice doping effects are considered to significantly contribute to the observed properties. Nitrogen atoms on pyrrolic positions were identified by XPS as the most stable site in a carbon network at high temperatures and thus affects the structure and magnetic properties of doped graphene. This type of doping will influence the reactivity and electronic and magnetic properties of any kind of carbon material with similar defects The multitude of positions and thus chamaeleon-like behavior of nitrogen atoms within the carbon network combined with their different influence on the electronic structure and magnetism indicates 
the necessity of a controlled tuning of the nitrogen doping. This can enable the preparation of new materials e.g. for conducting films and bulk carbons, electrochemical applications in supercapacitors and batteries and metal decorated supports for catalytic applications (by either not removing the transition metals incorporated by the synthesis or by adding PCP complexes of active transition metals into the dehalogenation route). Furthermore, the dehalogenation of perhalogenated precursors by a stoichiometric reaction with transition metals can be used for a straightforward and scalable preparation of novel (doped) carbon materials with graphene- type structural elements and a controlled surface termination in gram scales and similar reactions are feasible with other transition metals (e.g. $\mathrm{Fe}, \mathrm{Ni}, \mathrm{Co}, \mathrm{Mn})$, main group metals and intermetallic systems.

\section{EXPERIMENTAL SECTION}

Precursors $(0.8 \mathrm{mmol})$ of pentachloropyridine (PCP, 98\%, Aldrich) and hexachlorobenzene (HCB, 99\%, Fluka) were additionally purified by sublimation and introduced into quartz glass tubes (thickness: $1.5 \mathrm{~mm}$ ) with $\mathrm{Cu}$ grains $(99.5 \%, 5$ equivalents, Alfa Aesar), respectively. The ampoules were evacuated for $30 \mathrm{~min}$, sealed by melting and heated to $600^{\circ} \mathrm{C}, 800^{\circ} \mathrm{C}$ and $1000^{\circ} \mathrm{C}$ for 20 hours. Note for safety: The amounts used were calculated not to cause damage to the quartz ampoules. After the heat treatment, the ampoules were carefully opened with appropriate personal protection considering internal residual pressure (especially observed without the presence of copper). The recovered material was washed with hydrochloric acid $(\mathrm{HCl}, 37 \%$ in water) to remove residual copper by-products and dried for $12 \mathrm{~h}$ at $120^{\circ} \mathrm{C}$. Small amounts of $\mathrm{Cu}$-free samples were similarly prepared by direct heat treatment of the precursor. The morphology of the recovered samples was characterized by scanning electron microscopy (SEM; Zeiss LEO $1530 \mathrm{Gemini} ; 1.0 \mathrm{keV}$ ) and transmission electron microscopy (TEM; FEI Tecnai F20; $200 \mathrm{kV}$ ). Samples were sonicated in isopropanol for $1 \mathrm{~h}$, transferred to a carbon supported $\mathrm{Cu}$ grid and images were recorded quickly to minimize electron beam damages. X-ray powder diffraction (XRD) patterns were measured with a Bruker D8 diffractometer $(\mathrm{Cu} \mathrm{K} \alpha)$. The binding states of nitrogen atoms were characterized by X-ray 
Photoelectron Spectroscopy (XPS) with $\mathrm{Al} K \alpha$ excitation using a hemispherical electron analyzer (Scienta SES 100). The carbon materials were pressed onto an Indium foil, fixed on a molybdenum sample holder and measured in a customized UHV analysis chamber having a base pressure of $10^{-10}$ mbar. Raman spectra were measured using a BRUKER SENTERRA Spectrophotometer (488 $\mathrm{nm}$ ). The temperature- and magnetic field $(H(\mathrm{~T}))$ dependence of the magnetization $(M(\mathrm{emu} / \mathrm{g}))$ were measured with a Quantum Design MPMS-XL SQUID magnetometer up to a field of $5 \mathrm{~T}$ in a temperature range between 2 to $300 \mathrm{~K}$. Background signals from the sample holder and temperature independent contributions were subtracted.

Supporting Information Available: Figure S1 (XRD results of graphitic carbon materials obtained from PCP with/without $\mathrm{HCl}$ treatment); Figure $\mathrm{S} 2$ (temperature dependence of the magnetization of the obtained carbons with/without nitrogen obtained from different conditions at $1 \mathrm{~T}$ ); SI Table 1 (peak positions and line widths [in $\left.\mathrm{cm}^{-1}\right]$ of the Raman D, G and 2D modes and D/G mode intensity ratio's). This information is available free of charge via the internet at http://pubs.acs.org.

\author{
AUTHOR INFORMATION \\ Corresponding Authors \\ * sachdev@mpip-mainz.mpg.de; muellen@mpip-mainz.mpg.de \\ Present Address \\ \# WPI Advanced Institute for Materials Research, Tohoku University, Sendai; 80-8577, Japan.
}

\title{
ACKNOWLEDGMENT
}

K.M, H.S. and Y.I. acknowledge Funding for this work from the European Research Council for the FP7 Advanced Grant AdG-2010 267160 "NANOGRAPH" - The Chemist's Way of Making and Utilizing Perfect Graphenes. Part of this work was funded by the EC ITN GENIUS, the EU Project MoQuaS (Program No. FP7-ICT-2013-10 610449) and the DFG Priority Program Graphene. Valuable discussions with Prof. Dr. Martin Baumgarten are acknowledged as well as assistance of Martin Pfeffermann. 


\section{TOC and Graphical abstract for JACS}

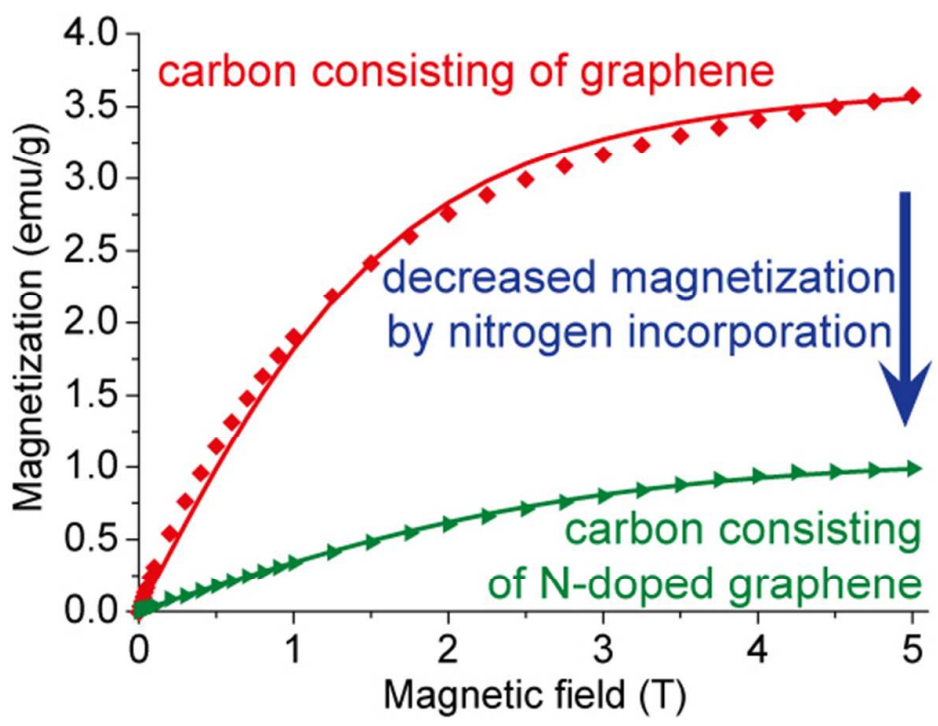

\section{REFERENCES}

(1) Müllen, K.; Antonietti, M. Macromolecular Chemistry and Physics, 2012, 213, 999-1000.

(2) Yang, S.; Feng, X.; Wang, X.; Müllen, K. Angew. Chem. Int. Ed. 2011, 50, 5339-5343.

(3) Qu, L.; Liu, Y.; Baek, J. B.; Dai, L. ACS Nano 2010, 4, 1321.

(4) Sheng, Z. H.; Shao, L.; Chen, J. J.; Bao, W. J.; Wang, F. B.; Xia, X. H. ACS Nano 2011, 5, 4350.

(5) Reddy, A. L. M.; Srivastava, A.; Gowda, S. R.; Gullapalli, H.; Dubey, M.; Ajayan, P. M. ACS Nano 2010, 4, 6337.

(6) Wang, Y.; Shao, Y.; Matson, D. W.; Li, J.; Lin, Y. ACS Nano 2010, 4, 1790.

(7) Wei, D.; Liu, Y.; Wang, Y.; Zhang, H.; Huang, L.; Yu, G. Nano Lett. 2009, 9, 1752.

(8) Guo, B.; Liu, Q.; Chen, E.; Zhu, H.; Fang, L.; Gong, J. R. Nano Lett. 2010, 10, 4975.

(9) Wang, X.; Li, X.; Zhang, L.; Yoon, Y.; Weber, P. K.; Wang, H.; Guo, J.; Dai, H. Science 2009, 324, 768.

(10) Jeong, H. M.; Lee, J. W.; Shin, W. H.; Choi, Y. J.; Shin, H. J.; Kang, J. K.; Choi, J. W. Nano Lett. 2011, 11, 2472.

(11) Wang, D. W.; Gentle, I. R.; Lu, G. Q. Electrochem. Commun. 2010, 12, 1423.

(12) Satoshi Yasuda, Li Yu, Jeheon Kima, Kei Murakoshi; Chem. Commun., 2013,49, 9627-9629.

(13) Usachov, D., Fedorov, A., Vilkov, O., Senkovskiy, B., Adamchuk,V.K., Yashina, L.V., Volykhov, A.A., Farjam, M., Verbitskiy, N.I., Grüneis, A., Laubschat, C., Vyalikh, D.V.; Nano Lett., 2014, 14, 4982-4988.

(14) Bagreev, A., Nanse, G., Lahaye, J.; Strelko, V.; Carbon, 1999, 37, 585-590.

(15) Schmiers, H., Friebel, J., Streubel P., Hesse, R., Kopsel, R.; Carbon, 1999, 37, 1965-1978.

(16) Kang E.T., Neoh K.G., Zhang X., Tan K.L., Liaw D.J.; Surf. Interface Anal. 1996, $24,51$.

(17) Fang, S., Jiang, Y., Wu,Y.;Solid State Ionics, 1999, 120, 117-123.

(18) G. Soto, E.C. Sámano, R. Machorro, F.F. Castillón, M.H. Farías, L. Cota-Araiza; Superfícies y Vacío 2002,15, 34-39.

(19) Ito, Y.; Christodoulou, C.; Nardi, M. V.; Koch, N.; Sachdev, H.; Müllen, K. ACS Nano, 2014, 8, 3337-3346.

(20) Wang, H.; Maiyalagan, T.; Wang, X. ACS Catal. 2012, 2, 781-794.

(21) Robertson, J.; Davis, C.A.; Diamond and Related Materials 1995, 4441-444.

(22) Rao, C. N. R.; Sood, A. K.; Subrahmanyam, K. S.; Govindaraj, A. Angew. Chem. Int. Ed. 2009, 48, 7752-7777.

(23) Lee, J.; Kim, J.; Hyeon, T. Adv. Mater. 2006, 18, 2073-2094.

(24) Fujita, M.; Wakabayashi, K.; Nakada, K.; Kusakabe, K. J. Phys. Soc. Jpn. 1996, 65, 1920-1923. 
(25) Klein, D. J.; March, N. H. Int. J. Q. Chem. 2001, 85, 327-344.

(26) Shibayama, Y.; Sato, H.; Enoki, T. Phys. Rev. Lett. 2000, 84, 1744-1747.

(27) Enoki, T.; Takai, K. Solid State Communications 2009, 149, 1144-1150.

(28) Enoki, T.; Kobayashi, Y.; Fukui, K. International Reviews in Physical Chemistry 2007, 26, 609-645.

(29) Batzill, M. Surface Science Reports 2012, 67, 83-115.

(30) Bekyarova, E.; Sarkar, S.; Niyogi, S.; Itkis, M. E.; Haddon, R. C. J. Phys. D: Appl. Phys. 2012, 45, 154009.

(31) Nair, R. R.; Sepioni, M.; Tsai, I-L.; Lehtinen, O.; Keinonen, J.; Krasheninnikov, A. V.; Thomson, T.; Geim, A. K.; Grigorieva, I. V. Nature physics, 2012, 8, 199.

(32) Parvez, K.; Yang, S.; Hernandez, Y.; Winter, A.; Turchanin, A.; Feng, X.; Müllen, K. ACS nano, 2012, 6, 9541-9550.

(33) Li, X.; Cai, W.; An, J.; Kim, S.; Nah, J.; Yang, D.; Piner, R.; Velamakanni, A.; Jung, I.; Tutuc, E.; Banerjee, S. K.; Colombo, L.; Ruoff, R. S. Science 2009, 324, 1312-1314.

(34) Varma, A.; Rogachev, A. S.; Mukasyan, A. S.; Hwang, S. Advances in Chemical Engineering 1998, 24, 79-226.

(35) Cudziło, S.; Huczko, S.; Pakuła, M.; Biniak, S.; Świątkowski, A.; Szala Cuzidlo, M. Carbon 2007, 45, $103-109$.

(36) Bystrzejewski, M.; Huczko, A.; Lange, H.; Cudziło, S.; Kiciński, W. Diamond and Related Materials 2007, 16, 225228.

(37) Takacs, L.; Progress in Materials Science 2002, 47, 355-414.

(38) Gogotsi, Y.; Nikitin, A.; Ye, H.; Zhou, W.; Fischer, J. E.; Yi, B.; Foley, H. C.; Barsoum, M. W. Nature Materials 2003, 2, 591-594.

(39) Moissan, H.; Electrique, L. F. Traite de Chimie Minerale, Masson \&Cie, Paris 1904.

(40) Tressaud, A. Angew. Chem. Int. Ed. 2006, 45, 6792-6796.

(41) Cai, J.; Ruffieux, P.; Jaafar, R.; Bieri, M.; Braun, T.; Blankenburg, S.; Muoth, M.; Seitsonen, A. P.; Saleh, M.; Feng, X.; Müllen, K.; Fasel, R. Nature, 2010, 466, 470-473.

(42) Binary Alloy Phase Diagrams (second edition): T. B. Massalski, (Ed.); H. Okamoto, P. R. Subramanian, L. Kacprzak, (Eds). ASM International, Materials Park, Ohio, USA 1990

(43) Micco, G. D.; Bohéc, A. E.; Pasquevich, D.M. J. Alloys and Compounds 2007, 437, 351-359.

(44) Lorenz, P. Acta Crystallor. 1956, 9, 538.

(45) Wells, A. F. J. Chem. Soc. 1947, 1670-1675.

(46) Arrigo, R.; Hävecker, M.; Wrabetz, S.; Blume, R.; Lerch, M.; McGregor, J.; Parrott, E. P. J.; Zeitler, J. A.; Gladden, L. F.; Knop-Gericke, A.; Schlögl, R.; Su, D. S. J. Am. Chem. Soc. 2010, 132, 9616-9630.

(47) Kondo, T.; Casolo, S.; Suzuki, T.; Shikano, T.; Sakurai, M.; Harada, Y.; Saito, M.; Oshima, M.; Trioni, M. I.; Tantardini, G. F.; Nakamura, J.; Phys. Rev. B 2013, 86, 035436.

(48) Sepioni, M.; Nair, R. R.; Rablen, S.; Narayanan, J.; Tuna, F.; Winpenny, R.; Geim, A. K.; Grigorieva, I. V. Phys. Rev. Lett. 2010, 105, 207205.

(49) Yazyev, O.V.; Rep. Prog. Phys. 73 (2010) 056501

(50) Janata, J.; Gendell; J.; Ling, C.-Y.; Barth, W. E.; Backes, L.; Mark, H. B.; Lawton, R. G.; J. Am. Chem. Soc., 1967, 89, 3056-3058.

(51) Yu, S. S.; Zheng, W. T.; Wen, Q. B.; Jiang, Q. Carbon 2008, 46, 537-543.

(52) Banhart, F.; Kotakoski, J.; Krasheninnikov, A. V. ACS Nano, 2011, 5, 26-41. 
ToC, Figures (1-6), Tables (1) and Supporting Information (S1,S2, SI Table 1) for

\title{
Tuning the Magnetic Properties of Carbon by Nitrogen Doping of its
}

\section{Graphene Domains}

\author{
Yoshikazu Ito ${ }^{1}$, Christos Christodoulou ${ }^{2}$, Marco V. Nardi ${ }^{2}$, Norbert $\mathrm{Koch}^{2}$, Mathias Kläui ${ }^{3}$, Hermann \\ Sachdev $^{1 *}$, Klaus Müllen ${ }^{1 *}$
}

Table of Contents and Graphical Abstract:

Tuning the Magnetism of Graphene and Carbon Materials by Nitrogen Doping

Yoshikazu Ito, Christos Christodoulou, Marco V. Nardi, Norbert Koch, Mathias Kläui, Hermann Sachdev, Klaus Müllen

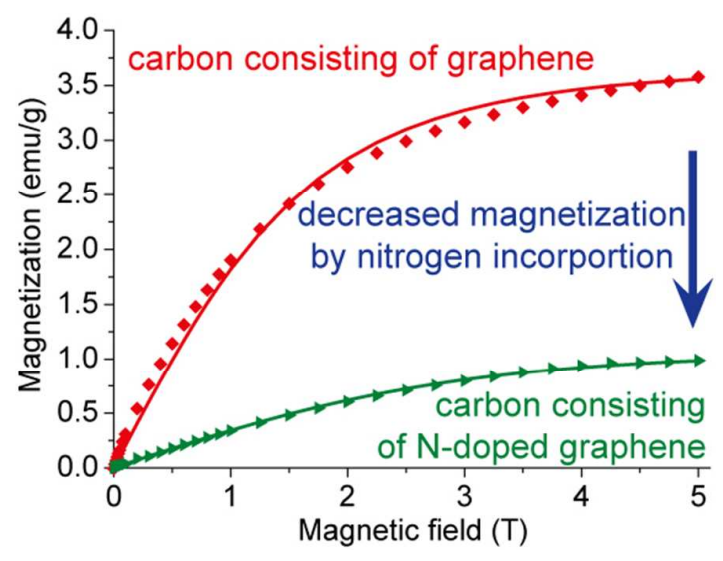


Figure 1

\section{Formation of Carbon} perhalogenated precursor (containing nitrogen)

(a)

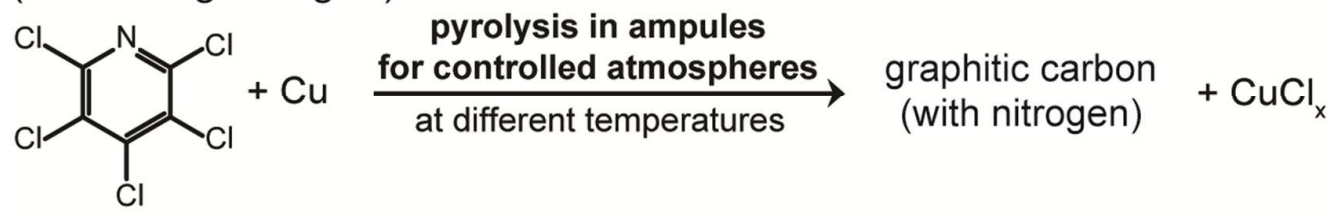

\section{Selected Nitrogen Sites}

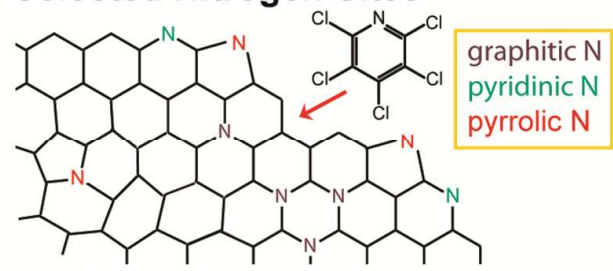

(b) graphitic carbon with nitrogen
Formal Interpretation of the Magnetism

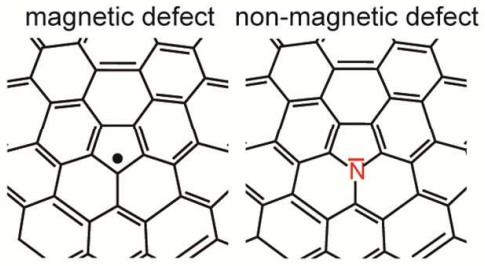

(c)

\section{Figure 1:}

Schematic illustration of the transition metal assisted dehalogenation of perhalogenated (hetero)aromatic precursors upon pyrolysis; b) potential active nitrogen sites in graphene; c) formal valence bond interpretation, structures and source of the origin for the observed magnetic properties from a chemical point of view indicated by the nitrogen electron lone pair 
Figure 2
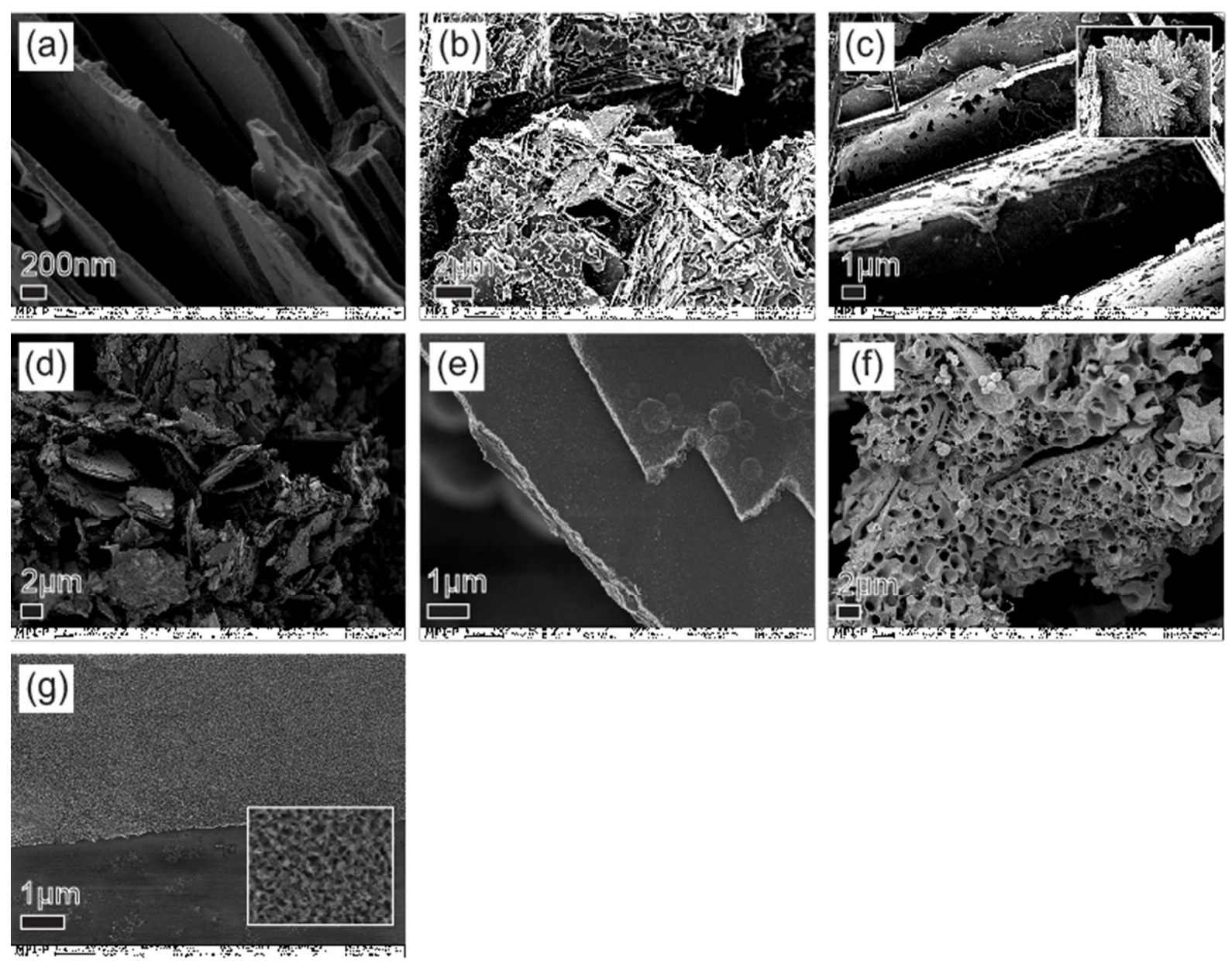

Figure 2:

SEM images of nitrogen containing carbon materials obtained from the reaction of PCP with an equilmolar amount of $\mathrm{Cu}$ and $\mathrm{Cl}$ (a) at $1000{ }^{\circ} \mathrm{C}$ (b) at $800{ }^{\circ} \mathrm{C}$ and (c) $600{ }^{\circ} \mathrm{C}$, (d) with a half equivalent of $\mathrm{Cu}$ and $\mathrm{Cl}$ at $1000{ }^{\circ} \mathrm{C}$, and (e) without any $\mathrm{Cu}$ at $1000^{\circ} \mathrm{C}$; and graphene containing carbon materials from $\mathrm{HCB}$ as a reference (without nitrogen): (f) from pyrolysis with an equimolar amount of $\mathrm{Cu}$ and $\mathrm{Cl}$ at $1000{ }^{\circ} \mathrm{C}$ and (g) from the neat decay without any $\mathrm{Cu}$ at $1000{ }^{\circ} \mathrm{C}$. 
Figure 3
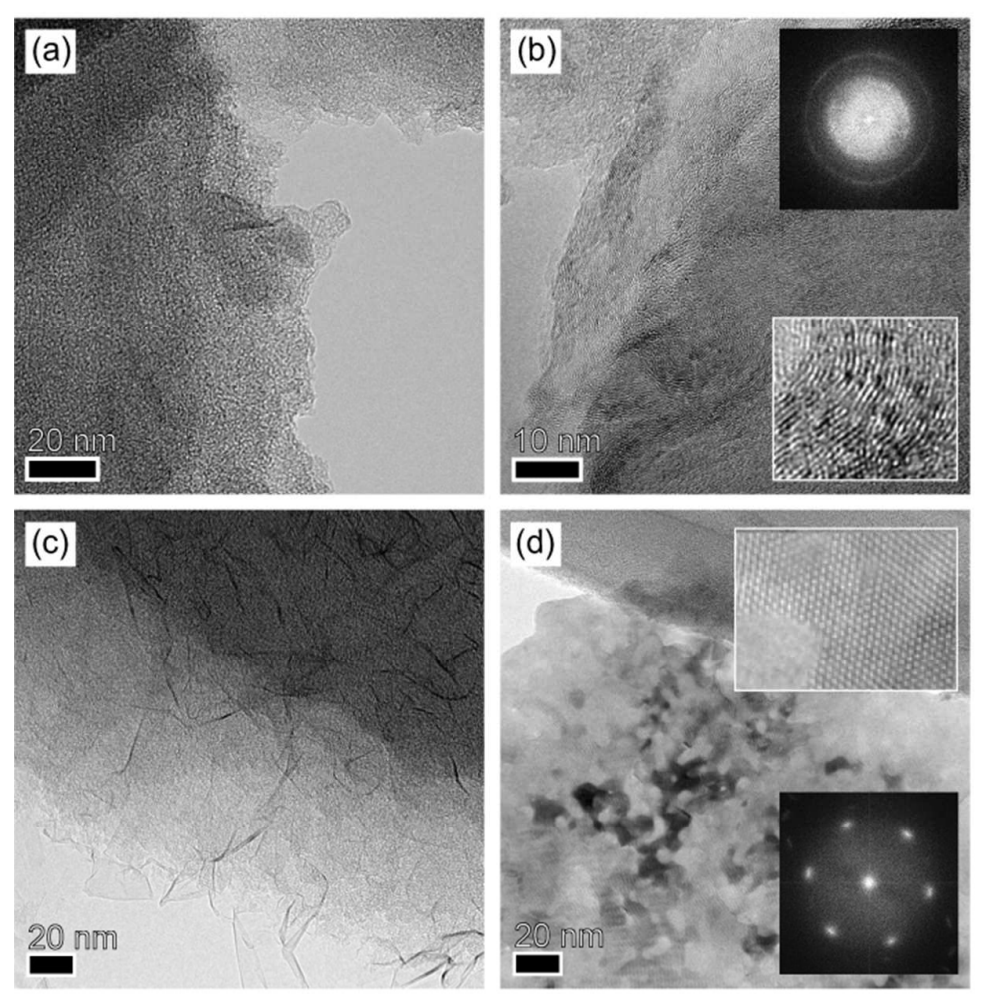

\section{Figure 3:}

TEM images from carbon obtained by the combustion synthesis: Nitrogen containing samples [a) PCP1000 HCl, b) PCP1000 non- $\mathrm{HCl}$ ] and nitrogen free samples [c) $\mathrm{HCB} 1000 \mathrm{HCl}$, d) $\mathrm{HCB} 1000$ non-HCl]. The insets of non- $\mathrm{HCl}$ treatment shows lattice spacing. FFT images in insets in (b) and (d) demonstrate randomly orientated graphene lattice and ordered graphene lattice, respectively and indicate a more ordered graphene formation from HCB. 
Figure 4
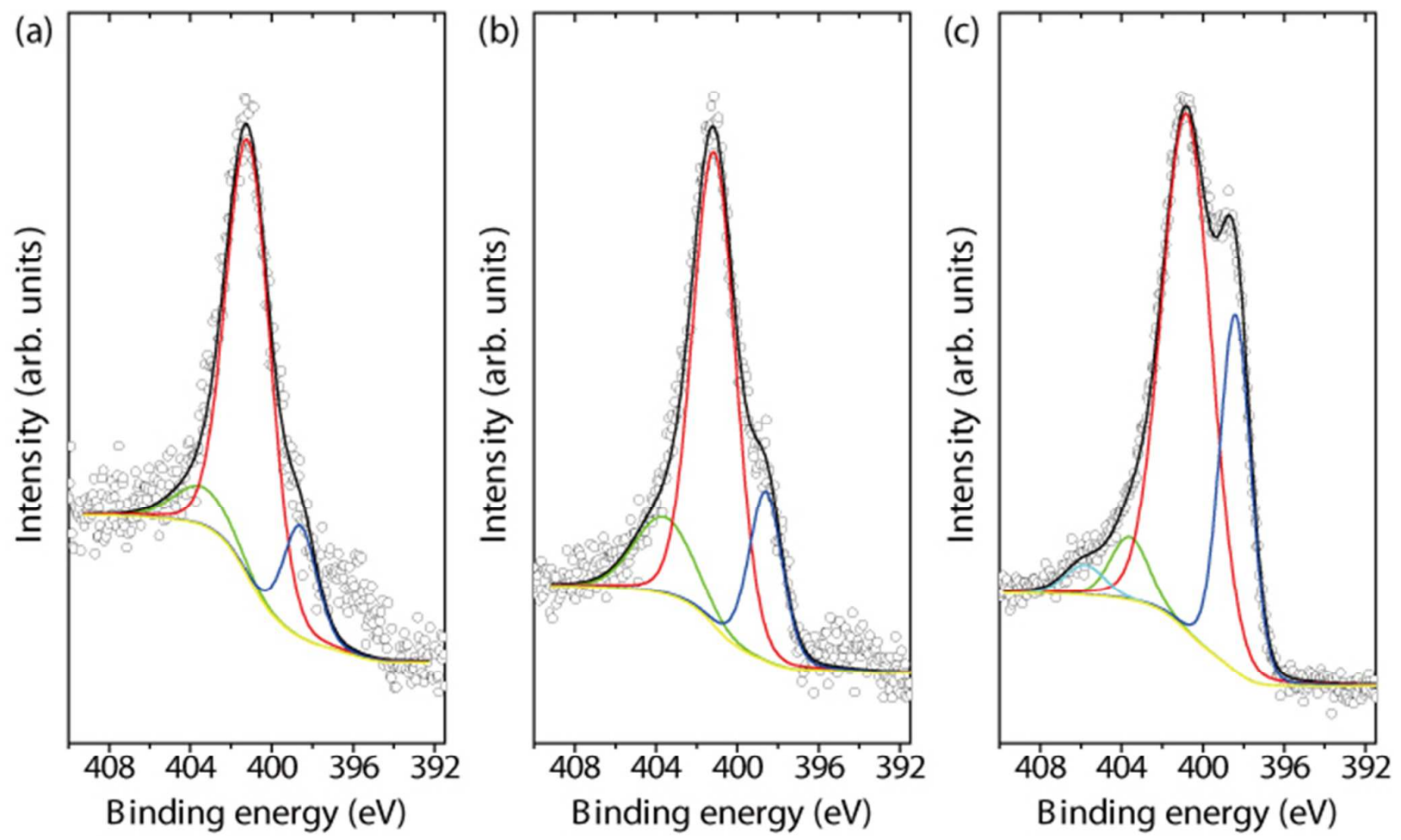

Figure 4: $\mathrm{N} 1 \mathrm{~s}$ core level spectra for a) $\mathrm{PCP} 1000-\mathrm{HCl}, \mathrm{b}), \mathrm{PCP} 800-\mathrm{HCl}$, and c) $\mathrm{PCP}-600-\mathrm{HCl}$. The contributions of pyridinic nitrogen (at $389.6 \mathrm{eV})$ and pyrrolic-graphitic nitrogen $(401 \mathrm{eV})$, as well as shake-up and potential oxidic nitrogen species at higher binding energy, according to the fitting routine, are included in the graphs. 
Figure 5

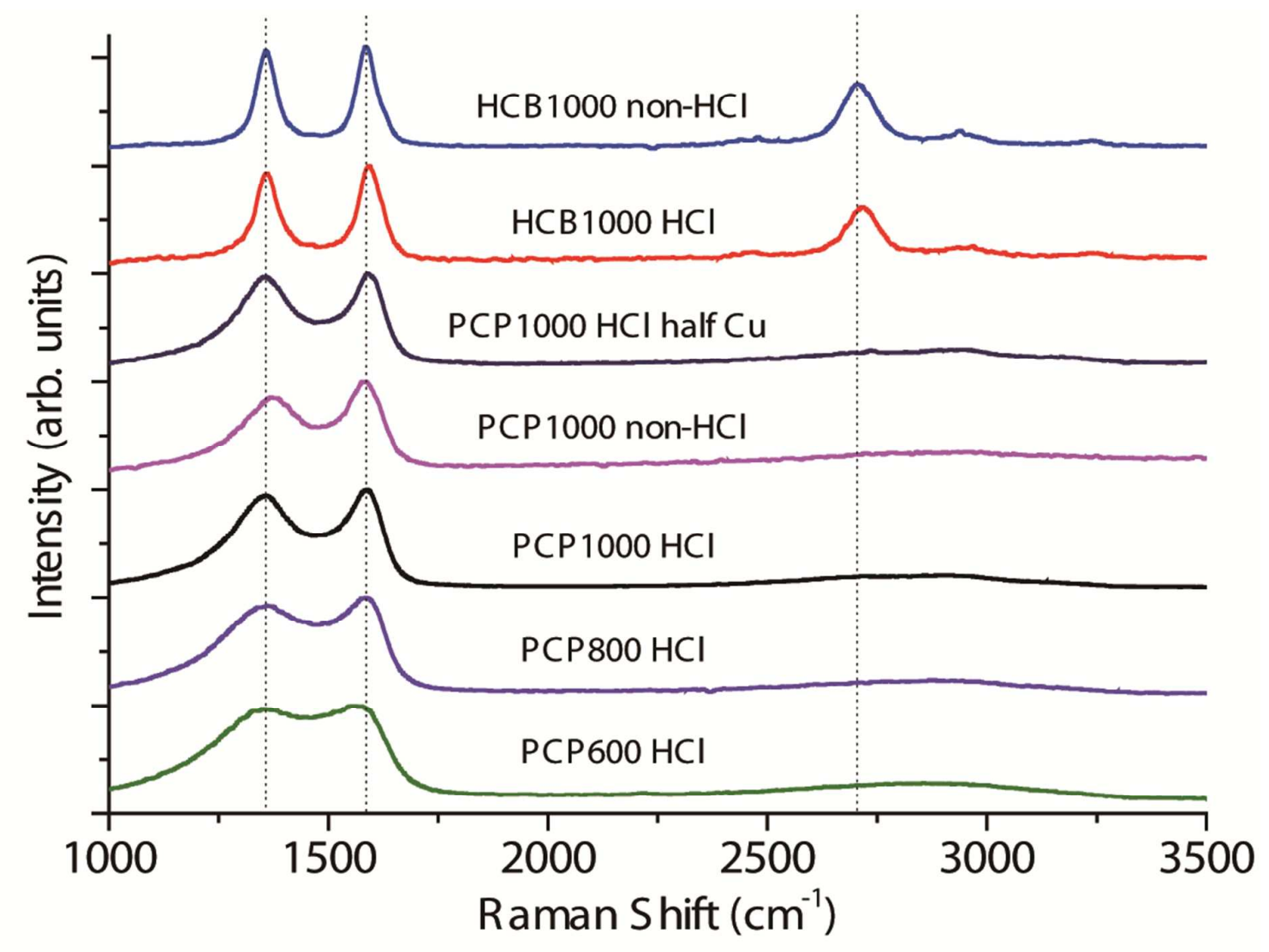

Figure 5:

Raman spectra of the reaction products obtained from transition metal dehalogenation of (nitrogen containing) perhalogenated PAH's 
Figure 6

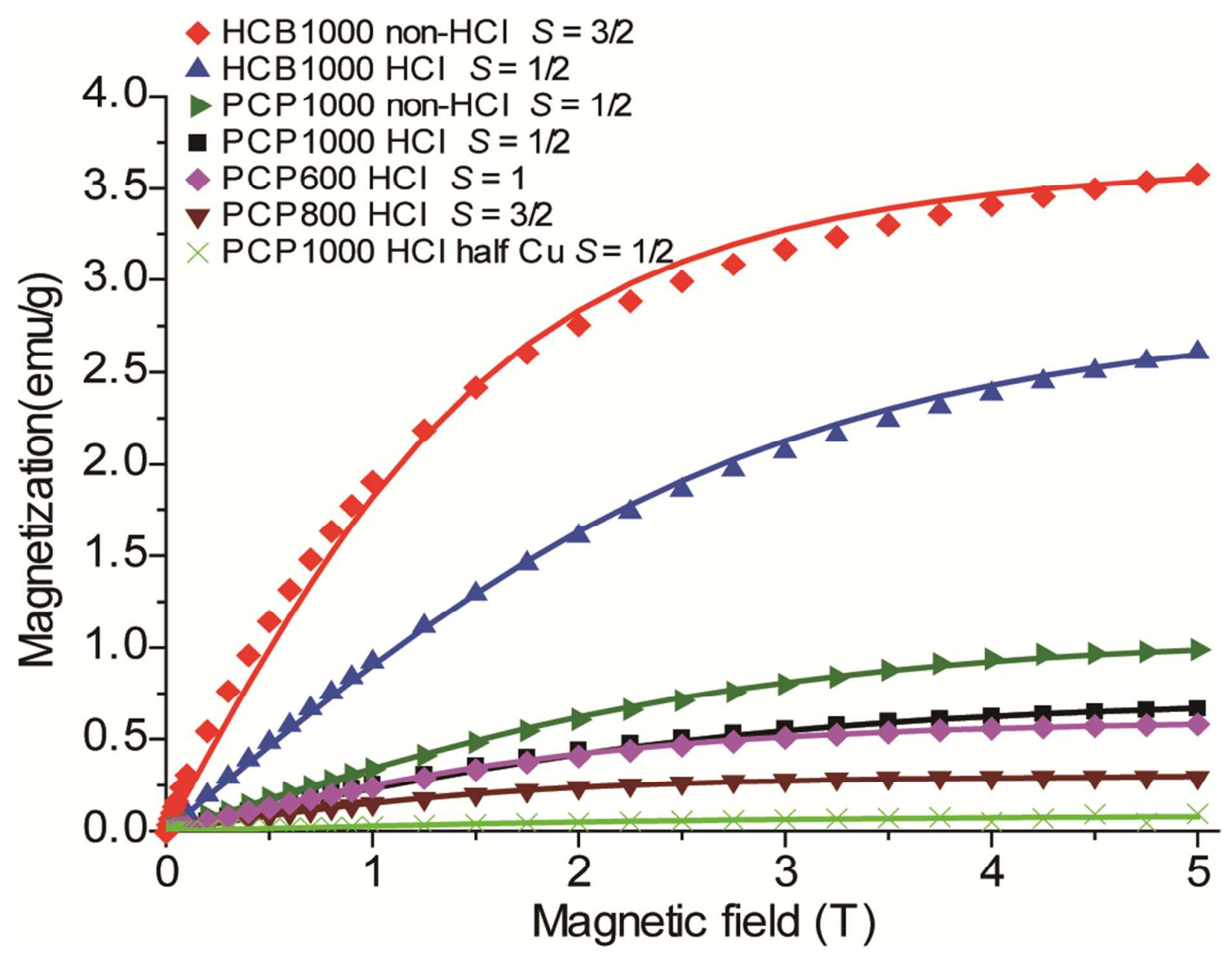

Figure 6:

Magnetization curves of graphitic carbon materials with/without nitrogen obtained from different reaction conditions. Solid lines show the Brillouin function for different spins. 


\section{Table 1}

\begin{tabular}{|c|c|c|c|c|}
\hline & $M(\mathrm{emu} / \mathrm{g})$ & $\chi_{0}\left(10^{-7} \mathrm{emu} / \mathrm{g}\right)$ & $N_{\mathrm{s}}\left(10^{19} \mathrm{spin} / \mathrm{g}\right)$ & Weiss temperature $(K)$ \\
\hline $\mathrm{HCB} 1000 \mathrm{HCl}$ & 2.6 & -5.8 & $30(S=1 / 2)$ & -2.1 \\
\hline $\mathrm{HCB} 1000 \mathrm{non}-\mathrm{HCl}$ & 3.6 & -2.1 & $13(S=3 / 2)$ & -2.7 \\
\hline $\mathrm{PCP} 1000 \mathrm{HCl}$ & 0.67 & -7.0 & $7.7(S=1 / 2)$ & -1.0 \\
\hline PCP800 HCl & 0.30 & -4.2 & $1.1(S=3 / 2)$ & -0.9 \\
\hline PCP600 HCl & 0.58 & -8.7 & $3.2(S=1)$ & -1.2 \\
\hline PCP1000 non-HCl & 0.99 & -6.9 & $11(S=1 / 2)$ & -2.2 \\
\hline PCP1000 HCl half $\mathrm{Cu}$ & 0.078 & -5.4 & $0.9(S=1 / 2)$ & -6.2 \\
\hline Nanographene & - & -7.3 & 4.2 & -2.5 \\
\hline
\end{tabular}

\section{Table 1:}

Magnetic properties of of the recovered carbon materials with or without nitrogen [magnetic saturation moment $(M)$, temperature independent susceptibility $\left(\chi_{0}\right)$, spin concentration $\left(N_{\mathrm{s}}\right)$ and Weiss temperature $(\mathrm{K})$ ] 